\title{
A Strategic Approach To Managing Customer Service Quality
}

Nelson Barber, University of New Hampshire, USA

Raymond Goodman, Jr., University of New Hampshire, USA

\begin{abstract}
Service quality is an essential strategy for success and survival in today's competitive environment. Earlier discussions emphasized what service quality meant to customers and how to develop strategies to meet customer expectations. More recently, the focus has shifted to understanding the impact of service quality on profit and other financial outcomes of the organization. Lowering customer defection rates can be profitable to companies, at the same time lowering employee turnover and improving their satisfaction and loyalty can also reduce customer defection and maintain or increase profits.
\end{abstract}

The purpose of this paper is to put forth an argument that to measure customer service quality is not only an important strategic approach, but is a critical and intertwined link to organizational commitment, communication, and employee satisfaction by improving and maintaining high standards of consistent service quality delivery. This strategic approach pulls together many previously tested models into a single workable assessment and feedback tool, with a particular focus on employee training, by establishing a strategic and measurable benchmarking index for continual monitoring and operational improvement.

Keywords: Service Quality; CIT; Employee Training; Indexed Gap

\section{CONCEPTUAL FRAMEWORK}

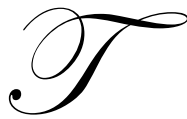

he increasing importance of customer satisfaction is uncontested. Yet, many service companies are facing a major challenge, meeting the changing needs of customers. Service quality has been the subject of considerable interest by both practitioners and researchers in recent years, prompted by the original work of Parasuraman et al. $(1985,1988)$. The main reason for the interest in service quality by practitioners is the belief that improving service quality will have a beneficial effect on a business's financial and operational performance.

Two important themes have emerged in the service quality research. First views service quality as the gap between expected level of service and the perception of actual performance received (e.g. Cronin and Taylor, 1992; Parasuraman, et al, 1985) and through numerous modifications the expectation assessment has changed to distinguish between desired and minimum expectations. The second view is set out by Gronroos $(1984,1990)$, who proposed a model that considered two related and measureable quality aspects: technical (output) and functional (process). In this model, technical is the deliverable to the customer, whether a meal in restaurant or a hotel room; while functional is concerned with how the output was delivered to the customer through established processes. This later quality indicator deals with both psychological and behavioral aspects which include accessibility to the provider, how service employees perform their task, what they say and how the service is delivered. Finally, Gronroos suggested that although technical quality can be assessed much easier, functional quality has its challenges. Bitner, Booms and Tetreault (1990) attempted to use qualitative measurement techniques to assess functional quality by categorizing various determinants of critical service encounters.

For this reason, the present study aims to suggest a strategic tool that considers the functional aspect of service quality, bridging the customer perception/expectation dichotomy, the effect that internal service quality has 
on employees' behavior, which is crucial for customers' perception of service quality, and training programs to insure functional quality is maintained to organizational standards. It is the contention of this conceptual model that although the functional quality aspect of service is critical to insuring quality delivery, there needs to be a connection, or "bridge" between the concepts of SERVQUAL and the qualitative work regarding behavioral aspects to create a seamless flow of feedback, assessment, modification, training, and then feedback that involves both customers and employees (staff and mangers). Therefore this study offers a strategic model that focuses on functional service quality as the driving force to improving service delivery and the customer's ultimate experience.

\section{Brief Summary of Service Quality Measurement}

The traditional services that once dominated the service sector - lodging, foodservice, housecleaning- have been increasingly supplemented by modern banking, insurance, computing, communication, and other business services (Eichengreen and Gupta, 2009). The growth in, and corresponding importance of the services sector in the US and the world is well-documented (Brady and Cronin, 2001; Brady, Cronin and Brand, 2002; Lui, 2005). The services industry in 2003 contributed on average 68\% of the global GDP, and in the United States generates over $85 \%$ of all new jobs and $66 \%$ of the GNP (Brady et al., 2002).

Interest in the measurement of service quality is understandably high and the delivery of higher levels of a service quality strategy is increasingly being suggested as critical to service providers' efforts in positioning themselves more effectively in the marketplace (Bienstock, DeMoranville and Smith, 2003; Johnston, 1995; Oh, 1999; Oh and Jeong, 1996). However, the problem inherent in the implementation of such a strategy has been identified by several researchers: service quality is an elusive and abstract construct that is difficult to measure and manage. In particular, academics and practitioners alike have exhibited considerable interest in the issues that surround the measurement of service quality and the conceptualization of the relationship between service quality and service delivery leading to consumer satisfaction. For example, Zeithaml, Berry and Parasuraman (1996) considered how service quality relates to retention of customers then tested for evidence of its impact on customers' behavioral responses.

Though initial efforts in defining and measuring service quality emanated largely from the goods sector, a solid foundation for research work in the area was put forth in the mid-eighties by Parasuraman, Zeithaml and Berry $(1985,1988)$. Parasuraman et al. $(1985,1988)$ provided a short definition of service quality. They defined service quality as 'a global judgment, or attitude, relating to the superiority of the service', and explicated it as involving evaluations of the outcome (i.e., what the customer actually receives from service) and processes of service act (i.e., the manner in which service is delivered). Being inherently and essentially intangible, heterogeneous, perishable, and entailing simultaneous production and consumption, services require a distinct framework for quality explication and measurement.

In line with the propositions put forward by Gronroos (1982) and Smith and Houston (1982), Parasuraman et al. $(1985,1988)$ posited 'operationalized' service quality is the difference between consumer expectations of 'what they want' and their perceptions of 'what they get.' Based on this conceptualization and operationalization, they proposed a service quality measurement scale called 'SERVQUAL.' The SERVQUAL scale constitutes an important landmark in the service quality literature and has been applied extensively in different service settings (Brady and Cronin, 2001).

Over time, variants of the scale have been proposed. The 'SERVPERF' scale is one such scale that was put forward by Cronin and Taylor (1992) in the early nineties. Cronin and Taylor (1992) suggested expectations were difficult to measure accurately and performance of the service was critical and more meaningful. The debates on the merits of SERVQUAL verse SERVPERF have been raging for the last two decades. Numerous studies (e.g. Bitner, 1990; Bolton and Drew, 1991, 1994; Teas and Palan, 1997; Zeithaml, Parasuraman, and Berry, 1990), have been undertaken to assess the superiority of the two scales, yet consensus continues to elude as to which one is a better measurement scale. 
Looking back on the past twenty five years since the first major measurement tool was developed (SERVQUAL) by Parasuraman et al. (1985), it has become apparent that the debate on how to define, measure customer expectations/ perceptions and performance, and close the reported "gap" between expectations and performance (see Figure 1) has added little to the overall measurement tools and number of assessment items that should be used.

What is lacking is a meaningful discussion of how to develop a management tool reflecting the gap between the customer's expectations and the business operations - specifically service delivery - such that strategies can be in place to minimize the gap. Blood (1974) suggested that behavioral expectation procedures could broaden service performance evaluation, particularly if developed from different perspectives. Goodman (1979) followed on this thought and suggested the use of the Critical Incident Technique to identify the attributes of service delivery particularly in the affective domain and subsequently for employee performance evaluation. These two studies considered the need to observe behaviors and related service incidents that both increase or decrease consumer satisfaction, develop the processes to determine how these incidents fit into the organizational goals, the relative importance of these incidents, and create appropriate initial employee hiring, training, and service information systems. Nearly twenty years later, Grapentine (1998) concluded from his extensive research on the assessment of service quality that too much focus had been on measuring customer satisfaction or expectations and far too little spent on connecting customer needs to business processes supporting the work of Blood (1974) and Goodman (1979). Grapentine (1998) suggested that organizations need to determine how to establish measurement scales that should facilitate the interface between the assessment process and organizational change that leads to continuously improving service delivery.

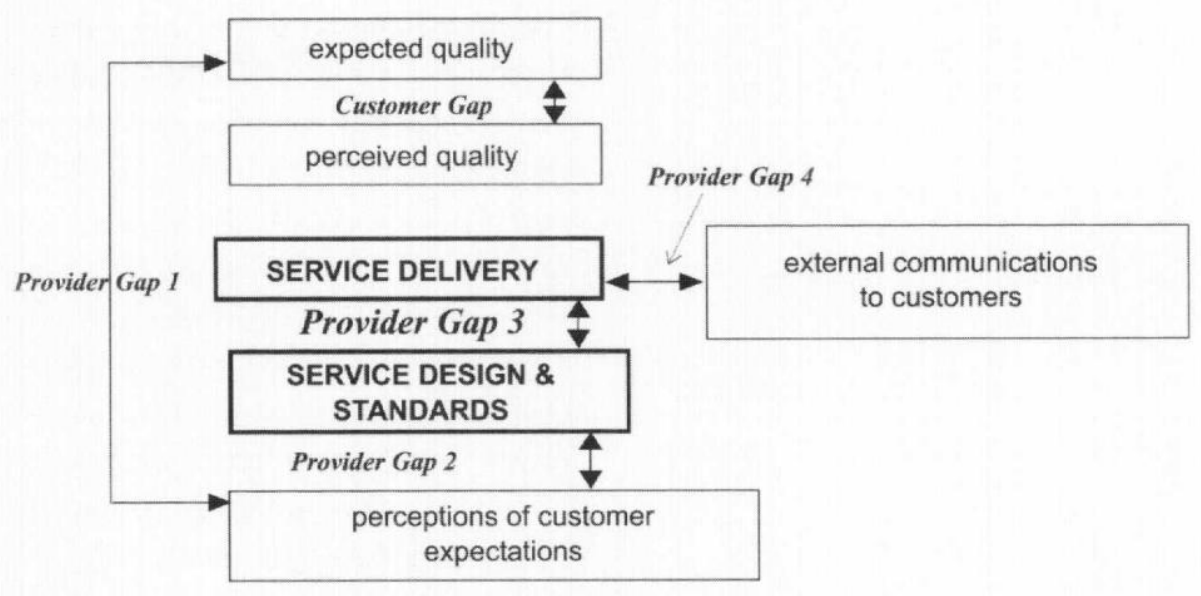

Figure 1 Adapted from Parasuraman et al. (1985)

Recently, Bienstock et al. (2003) considered how organizational citizenship behavior related to service quality. They considered that, by assessing what motivates service employees in relation to organizational standards and customer perceptions of service quality, the important provider gap between service delivery and service design and standards could be addressed. Yet this study did not consider a critical component of Gap 3 as discussed by Zeithmal et al. (1990). Gap 3 suggests the importance of not only recognizing customers' needs and designing appropriate standards, but the need of maintaining a well - trained workforce that is "shoulding" (from psychologist Clayton Barbeau telling one's self that you have an obligation to do something different from what you are doing) and able to perform at required levels for service delivery. By only focusing on Gap 3, the extended gap model, and by not considering the other key factors of this gap, such as employee-fit or role conflict, Bienstock et al. (2003) addressed part of the real need for developing strategies to close the service gap between customer perceptions and expectations of service quality. 


\section{Quality and Understanding the Service Encounter as a Strategic Tool}

At the same time the discussion on measurement of service quality from the customers' perspective was starting, research was also underway from a different perspective. Customer satisfaction, an often-expressed fundamental goal of organizations on both sides of the product-service dichotomy, was taking on added significance in service industries from the standpoint of employees. Indeed, service organizations such as hospitals, retirement communities, hotels, restaurants are highly dependent upon their employees' ability to consistently provide the "right" service in the "right" fashion to the consuming public (Goodman, 1979). Critical to this process is the interaction between service employees and customers and the resulting evaluation formed by the customer based upon this interaction. Solomon, Surprenant, Czepiel and Gutman (1985) suggested that some service firms have directed their understanding of the importance the service encounter plays through the recognition of the marketing role all front-line personnel have. This concept draws on their earlier work suggesting that service encounters are role performances in which both customers and service providers have roles to enact. This use of the term "service encounter" focuses on the interpersonal element (the affective domain of behavior) a service firm's performance exhibited by each interpersonal connection with and between an employee and a guest, patient, resident, and so forth. Long ago, these encounters were referred to as "moments of truth" (Brady and Cronin, 2001; Carlzon, 1987; Lui, 2005).

From the perspective of management, identifying those qualities and behaviors that customers value and relate to good service quality has come to be recognized as a strategic tool for attaining operational efficiency and improved business performance (Blood, 1974; Goodman, 1979; Berry and Parasuraman, 1997). This is true for both the goods and services sectors. Bitner, Booms and Tetreault $(1989,1990)$ suggested that the service encounter represents a period of time when a consumer directly interacts with a service--the simultaneity of production and delivery of the service encounter.

However, the problem with management of service quality in service firms, as discussed earlier, is that quality is not easily identifiable and measurable due to inherent characteristics of services which make them so distinctly different from goods. Jain and Gupta (2004) noted that, because of the various definitions of the term 'service quality' proposed in the past, different scales for measuring service quality have been advanced. An ideal service quality scale is one that is not only psychometrically sound (measuring knowledge, abilities, attitudes, and personality traits), but the scale is also analytically robust to provide insights to the managers for corrective actions in the event of quality shortfalls. From the management perspective, Goodman (1979) suggested the qualities and behaviors customers' value and link to good service must be identified. Then appropriate training can be developed to insure the service delivery is made consistently. This concept is what Solomon et al. (1985) suggested when discussing the importance of role performance. Effective management of the service encounter involves understanding the often complex behaviors of employees that can distinguish a highly satisfactory service encounter from a dissatisfactory one, and then training, motivating, and rewarding employees to exhibit those behaviors determined to be satisfactory by both organizational members (e.g. employees and managers) and recipients of the service.

One possible approach to understand what qualities and behaviors customers' value is to consider a servicequality information system (Berry and Parasuraman, 1997; Bitner et al., 1990). A service-quality information system uses multiple research approaches to systematically capture, organize, and disseminate service-quality information to support organizational decision making. According to their study, a multiple research approach is beneficial as each individual approach has limitations and strengths, but by combining multiple research approaches, a firm can tap into the strengths of each and compensate for weaknesses of others. For example, Berry and Parasuraman (1997) suggested the primary test of a service-quality information system is the extent to which it informs and guides service improvement decision making. Another important test is the extent to which the system motivates both managerial and non-managerial employees to improve service. They discussed five guidelines for developing an effective information system:

1. Measure service expectations.

2. Emphasize information quality.

3. Capture customers' words. 
4. Link service performance to business results.

5. Reach every employee.

As suggested by Berry and Parasuraman (1997), measuring service performance alone is not as meaningful as measuring performance relative to customer expectations. For example, they cited a service performance score of 7.3 (on a 9 point scale) measuring "performs the service right the first time" as difficult to interpret without a reference point of what the customer expected. If the customer expectation score was 8.3 on the same measure, would the organization need to evaluate its internal processes? This "gap" between expectation and performance align with Parasuraman et al. $(1985,1988)$ Gap 5 and could be used to create a strategic index. Thus the core success factors embedded are the treatment of external, competitors' and internal customers through the use of multiple measures and ongoing measurement. A well-designed and -implemented service-quality information system raises the probability that a company will invest service improvement monies in ways that actually improve service. It also underscores continually the need to improve service. Continually capturing and disseminating data reveal not only progress, but problems; not only strengths, but weaknesses (Berry and Parasuraman, 1997). Thus, continuous data collection and dissemination informs and educates decision makers about the patterns of change such as the shifting service priorities of customers.

\section{Service Profit Chain Model}

The service-profit chain (SPC) is a framework for linking service operations, employee assessments, and customer assessments to a firm's profitability (Heskett, Jones, Loveman, Sasser and Schlesinger 1994). The serviceprofit chain establishes relationships between profitability, customer loyalty, and employee satisfaction, loyalty, and productivity. The links in the chain are as follows: profit and growth are stimulated primarily by customer loyalty. Loyalty is a direct result of customer satisfaction. Satisfaction is largely influenced by the value of services provided to customers. Value is created by satisfied, loyal, and productive employees. Employee satisfaction, in turn, results primarily from high-quality support services, policies that enable employees to deliver results to customers creating an information feedback loop.

A similar model, "the cycle of success," proposed earlier by Schlesinger and Heskett (1991) suggest that employee satisfaction leads to high quality of service and customer satisfaction. According to Wilson and Frimpong (2004), the "Cycle of Success" also expressed as "the job satisfaction-service performance/quality thesis" is based on theories such as attitude-behavior (Fishbein \& Ajzen, 1975), equity (Adams, 1965), and social exchange theories (Blau, 1964). The logic of "the cycle of success" relies on satisfied workers deliver better quality of service to both workmates (who are on the front line) compared to both customers than employees who have lower job satisfaction.

An important staring point to creating an internal service quality and cycle of success is the conceptual model (See Figure 2) of organizational functioning proposed by Nadler (1971), tested by Goodman (1979) and supported by Ostroff and Bowen (2000). In the Ostroff and Bowen (2000) model, contextual social factors and the human resource (HR) system lie at the start of a hypothesized causal chain. According to Ostroff and Bowen (2000), a fair and consistent HR system communicates positive and clear signals to employees and fosters the development of positive perceptions of what the organization is like toward a favorable shared climate. Climate, in turn, influences employee attributes such as commitment, motivation, and identification with the organization. Positive attitudes lead to salient employee behaviors such as attachment (attendance and staying with the organization), performance (execution of in-role tasks), and citizenship (discretionary pro-social behaviors) that increase organizational productivity. Empirical evidence for such linkages has been reported by Simons and Roberson (2003). Within this framework, the service profit chain may be described as follows: climate influences employee commitment, and employee commitment influences both customer satisfaction and sales. Furthermore, because the service profit chain model claims that sales achievement results from increased customer satisfaction, it follows that customer satisfaction should mediate the relationship between commitment and sales. 


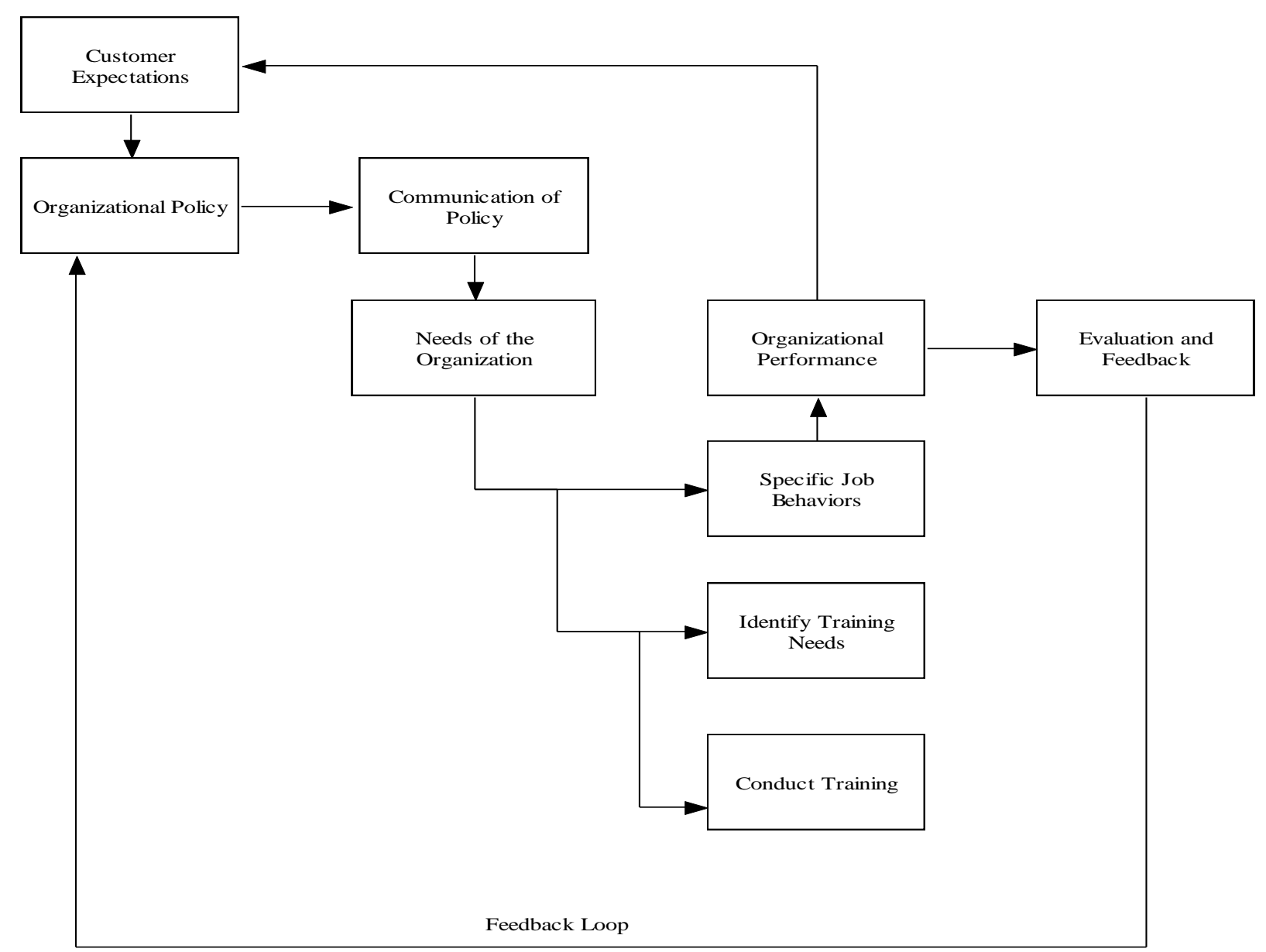

Figure 2, Modified from Goodman (1979) and Nadler (1971).

\section{Critical Incident Theory and Development of Service Standards Model}

As suggested in the discussion above, to establish appropriate service delivery polices and standards through an effective HR system and to make necessary changes to service delivery processes, management must identify the customer qualities and behaviors deemed of value to the customers. The Critical Incident Technique (CIT), researched and tested by Goodman (1979), has received limited research in the services literature. CIT, which has its roots in behaviorally anchored rating scales (BARS), can be used for many purposes such as employee selection and placement, training program criteria, employee performance evaluation (Goodman, 1979; Jacobs, Kafry and Zedeck, 1980). Many studies have been conducted and published which offer information regarding BARS as a system of performance appraisal. Jacobs et al (1980) cited the work by Blood (1974) that by utilizing data obtained in or expanding the BARS procedure, it is possible to extend the domain of evaluated performance, develop training programs, and assess agreement on and communication of organizational policy. For example, the most basic question to address regarding performance evaluations is why they are being conducted. This was answered by Jacobs et al. (1980) when they suggested that the reasons range from noting negative critical behaviors to be stored for future use in disciplinary/ dismissal actions to monitoring performance in the expectation of relaying useful information to improve future performance. Perhaps the most vital decision regarding uses of performance evaluations can be dichotomized as needs of the individual versus needs of the organization. Thus, BARS has the potential to increase organizational communication regarding levels of performance indicated by different behaviors. If behavioral items are rated by many supervisors/managers, discrepancies within and between organizational levels regarding the values assigned to behaviors can be uncovered and discussed (Blood, 1974; Jacobs et al., 1980). 
To capture the relevant data, CIT is used as an interview technique, where the informants are encouraged to talk about organizational incidents, instead of answering direct questions, thus deemphasizing the inclusion of general opinions about management and working procedures, focusing instead on specific service-related incidents (Goodman, 1979). These observations are kept track of as unique incidents which are then used to solve practical problems and to develop broad psychological principles. A critical incident can be described as one that makes a significant contribution - either positively or negatively - to a service activity, encounter, or phenomenon. Critical incidents can be gathered in various ways, but typically respondents are asked describe a situation about an experience they have had or observed.

CIT as a method of classification can be categorized with other inductive grouping procedures such as factor analysis, cluster analysis, and multidimensional scaling (Hunt 1983, p. 354). Such methods determine categories based on analysis of a specific set of data and are particularly useful when there is little documentation of the properties that are likely to be important for classifying. Unlike the other grouping procedures, however, CIT uses content analysis of behavioral incidents, rather than quantitative solutions, in the data analysis stage of the procedure. Content analysis "takes the communications that people have produced and asks questions of the communications" (Goodman, 1979). However, given the sophistication of statistical software today, meaningful quantitative analysis can be performed to aid and support the analysis of respondent data.

Bitner et al. $(1989,1990)$ studies focused on service encounters providing an example of how the CIT method could be applied to service research. They analyzed 700 critical service encounters in three industries (airlines, hotels, and restaurants) from the perspective of the customer. As a result of this effort, they found that unprompted and unsolicited employee actions, whether pleasing or unpleasing to the customer, are less subject to management control. Even the best employees have bad days. However, recruitment and selection procedures can be used to hire employees with a strong service attitude. They suggested that a strong service culture, effective supervision and monitoring, with quick feedback to employees will control, to some extent, the seemingly random occurrence of employee behaviors. They also found that the critical incident method is a useful tool for assessing customer satisfaction, or dissatisfaction, in service encounters. Using the CIT method can uncover specific events and behaviors that underlie service encounter satisfaction, which can be used as a base for developing customer satisfaction monitoring programs, designing service procedures and policies, and training contact personnel. Thus, the CIT method, they suggested, enables the researcher to get behind general concepts as "friendly, efficient, professional" to the actual contact employee behaviors linked to those concepts. This led to the identification of three types of employee behaviors (recovery, adaptability, and spontaneity) as sources of satisfaction and dissatisfaction in service encounters.

Gremler (2004) cited studies that have used the Critical Incident Technique (CIT) in a variety of service contexts. For example, Arnould and Price's (1993) examined the extended service encounter by investigating a context in which an extraordinary service experience, whether positive or negative, are important and can occur in service encounters that may continue for several days. Kelley, Hoffman, and Davis's (1993) study developed a typology of retail failures and recoveries, a direct result of wanting to extend the work of Bitner et al. $(1989,1990)$ in the area of service recovery. Bitner, Booms, and Mohr (1994) employed the CIT method to examine the service encounter from the perspective of the firm - specifically, the customer-contact employee, thus expanding their initial framework by identifying a fourth group of behaviors (employee response to problem customers, labeled coping). Finally, Stauss and Mang (1999) suggested the CIT method as offering a number of benefits: the most important of which is that collected data are from the respondent's perspective and in his or her own words which is particularly well suited for use in assessing perceptions of customers and employees from different cultures.

\section{PROPOSED METHODOLOGY}

\section{Bridging the Service Quality Models}

Service quality is an elusive and indistinct characteristic, often mistaken for vague adjectives like exceptional or magnificent. Service quality and its requirements are not easily expressed by consumers supporting research that captures customers' views on performance. Explanation and measurement of service quality also present problems for researchers who often bypass definitions and use uni-dimensional self-reporting measures to capture the explanation and measurement of service quality. 
The conceptual work in this paper proposes to bring together many of the service quality models that have been tested individually or in various combinations into a single, workable, and strategic measurement assessment tool. This proposed methodology is not to suggest assessment and action items for each of the four service gaps individually, but rather to put forward a strategic course of action to bridge all the gaps in such a way that a meaningful plan can be adopted by organizations for improved service delivery consistent with organizational policy. The quantitative and qualitative scientific methodology developed here is designed to be tested in unique settings (such as restaurants, retirement communities, lodging, banking and car rental) or transferable across service quality applications in other sectors of the service industry. In other words, this universally applicable methodology has "broken the code" of prior research models through the combining of many individualized research methodologies into the proposed Lego Model in Figure 3, thereby avoiding the need to test individual models to determine the most strategic approach for improving service quality.

The development of the proposed methodology will follow the work performed by Blood (1974) where he discussed the aspects of behavioral expectation assessment as a means to develop training programs, assess the agreement on organizational policy, and the communication of the organizational policy to employees and managers. To implement the plan, the proposed methodology will use the work by Goodman (1979) where he suggested using and tested the need to identify the dimensions on which service delivery can be observed and measured with the key drivers of this technique for the use of hiring practices, employee placement, employee training, and operational performance evaluation. Finally, the proposed methodology will link the service quality information system guidelines developed by Berry and Parasuraman (1997), such as measuring service expectations, capturing customer and employee descriptors, and linking performance to business results, and to create an overall service information feedback system.

The proposed assessment model in Figure 3 sets out, through eight objectives, the frame work for this methodology. In summary this proposed methodology, using techniques such as self-report surveys, Critical Incident Theory, and organizational communication assessment, will:

1. Assess customer service quality expectations and organizational performance, to enhance employees service delivery and ultimately improve organizational performance

2. Assess organizational internal service quality

3. Determine what makes an effective service employee

4. Identify training needs

5. Determine needs of the organization and its policy

6. Determine how policy is communicated

7. Establish a training approach that supplements and complements knowledge (cognitive domain), taskanalysis (psychomotor domain) and skill training methods (psychomotor domain), by focusing on behaviors directly associated with job performance (affective domain)

8. Re-assess customer service quality expectations and organizational performance, to enhance employees' service delivery and ultimately improve organizational performance.

Using the eight objectives stated above and the model in Figure 3, the proposed methodology was segmented into 6 phases. Alone, each phase of the proposed research, based upon prior research, does not close the loop on improving service quality. For example, although it has been argued (e.g. Bitner, 1990; Bolton and Drew, 1991, 1994; Cronin and Taylor, 1992; Parasuraman et al., 1985, 1988; Teas and Palan, 1997; Zeithaml, Parasuraman, and Berry, 1990) that assessing consumers expectations against performance has it merits, these measures alone do not allow for adjustments to internal or external service delivery. In fact, Cronin and Taylor (1992) argued expectations were difficult to measure accurately and performance of the service was critical and more meaningful. At the same time Blood (1974), Goodman (1979), and Grapentine (1998) suggested that a connection with behaviors and expectations/performance was necessary to understand and improve service quality, in particular through training measures. Thus, by combining the prior models may provide a better tool for improving service quality delivery. 


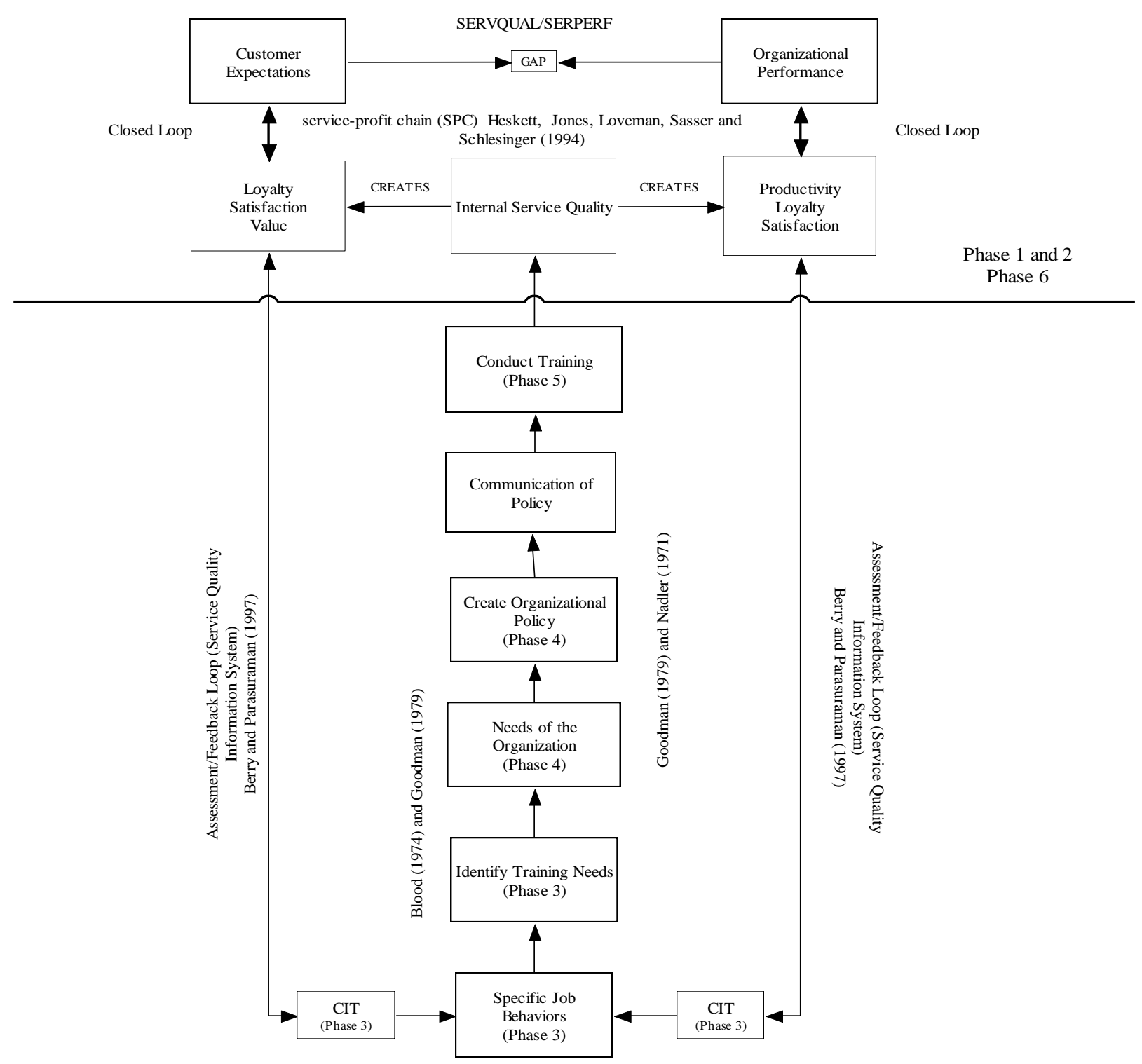

Figure 3. Lego Model ${ }^{\mathrm{TM}}$ (created by and trademark protected by current authors)

\section{Methodology Design}

Table 1 links the eight objectives, six phases, examples of the previous research, to Figure 3 allowing the readers to follow the model and discussion.

The first phase would be to assess customer service quality expectations and organizational performance, to enhance employees' service delivery, and ultimately improve organizational performance. This should be accomplished by using modified versions of the work performed by Parasuraman et al. $(1985,1988)$, Brown and Swartz (1989), Zeithaml et al. (1990), and Cronin and Taylor (1992). The measurement should consider the two areas of customer expectations of service quality and customer perception of the actual service delivery by an organization. The purpose is to fold: first to measure desired service (what the customer believes the service should be and can be) and second the adequacy of service delivery (the minimal level of service acceptable to the 
customer). Service performance is superior if perception scores exceed the zone of tolerance, acceptable if perceptions are within the zone, and unacceptable if perceptions are below the zone. Comparing the perceptionsonly data with the combined perceptions-expectations data demonstrates the diagnostic value of measuring customers' expectations. An indexed gap between expectations and performance should be created from the first phase of this study.

Table 1. Summary of Proposed Model Methodology

\begin{tabular}{|c|c|c|}
\hline Methodological Objectives & $\begin{array}{c}\text { Suggested } \\
\text { Phases } \\
\text { (See Figure 3) } \\
\end{array}$ & $\begin{array}{c}\text { Examples of Previous Research in support of } \\
\text { Objectives }\end{array}$ \\
\hline $\begin{array}{l}\text { 1. Assess customer service quality expectations and } \\
\text { organizational performance, to enhance employees } \\
\text { service delivery and ultimately improve } \\
\text { organizational performance }\end{array}$ & Phase 1 & $\begin{array}{l}\text { Gronroos (1982); Smith and Houston (1982); } \\
\text { Parasuraman et al. (1985, 1988); Cronin and } \\
\text { Taylor (1992) }\end{array}$ \\
\hline 2. Assess organizational internal service quality & Phase 2 & $\begin{array}{l}\text { Schlesinger and Heskett (1991); Heskett, Jones, } \\
\text { Loveman, Sasser and Schlesinger (1994); } \\
\text { Wilson and Frimpong (2004); of Pritchard and } \\
\text { Silvestro (2005) }\end{array}$ \\
\hline 3. Determine what makes an effective service employee & Phase 3 & Goodman (1979) \\
\hline 4. Identify training needs & Phase 3 & Goodman (1979) and Nadler (1971) \\
\hline 5. Determine needs of the organization and its policy & Phase 4 & $\begin{array}{l}\text { Blood (1974), Berry and Parasuraman (1997), } \\
\text { and Jacobs et al. (1980) }\end{array}$ \\
\hline 6. Determine how policy is communicated & Phase 4 & $\begin{array}{l}\text { Blood (1974), Berry and Parasuraman (1997), } \\
\text { and Jacobs et al. (1980) }\end{array}$ \\
\hline $\begin{array}{l}\text { 7. Establish a training approach that supplements and } \\
\text { complements knowledge (cognitive domain), task- } \\
\text { analysis (psychomotor domain) and skill training } \\
\text { methods (psychomotor domain), by focusing on } \\
\text { behaviors directly associated with job performance } \\
\text { (affective domain) }\end{array}$ & Phase 5 & Goodman (1979) and Nadler (1971) \\
\hline $\begin{array}{l}\text { 8. Re-assess customer service quality expectations and } \\
\text { organizational performance, to enhance employees' } \\
\text { service delivery and ultimately improve } \\
\text { organizational performance. }\end{array}$ & Phase 6 & Follow phase 1 above \\
\hline
\end{tabular}

The second phase of the research study is to assess organizational internal service quality. This was accomplished by following the work of Pritchard and Silvestro (2005) and Heskett et al. (1994). Employee surveys, assessing expectations, performance, satisfaction, would be performed. Examples of the chosen measurement criteria for each element of the service profit chain are (shown in Table 2), internal service quality; service capability, employee and Customer Satisfaction should all be measured on the basis of perceptual survey data. A mixture of soft and hard measures of employee and customer loyalty should be adopted. An indexed gap between expectations and performance should be created from this phase of the study.

The third phase (Objectives 3 and 4) of the study is set-up to determine what makes an effective service employee and identify training needs. This portion of the proposed methodology follows the CIT work of Goodman (1979) as outlined below where two separate groups of service workers were beta-tested. The first were 78 waiter/waitresses, their managers, and second level managers in 10 different locations to include casual dining, private clubs, coffee shops, and fine dining. The second were 78 nursing home employees, residents (patients), and sponsors in New York. For each of these studies, participants were asked to write 10 incidents (see Table 3 for an example) where they witnessed either their own behavior or another's behavior in performing a job task.

Each of the two studies collected on average 800 raw incidents. The original data base was then culled to just over360 incidents/behaviors where a second questionnaire was created asking the same subset of original participants to rate these incidents on an 8-point importance scale from not important to very important. The resulting importance behaviors were then scaled within 6 dimensions (e.g. guest relations, supervisor relations, 
relations with co-workers) from most important to least important. The final dimensions were created using a panel of experts to sort the incidents which then served as training dimensions for phase.

Table 2. Performance Measures to be used in the Study for Internal Service Quality

\begin{tabular}{|c|c|}
\hline Elements of Service Profit Chain & Measurement Criteria \\
\hline \multirow[t]{5}{*}{ Internal Service Quality } & At work my opinions seem to count \\
\hline & $\begin{array}{l}\text { In the last seven days I have received recognition or praise for } \\
\text { doing good work }\end{array}$ \\
\hline & I know what is expected of me at work \\
\hline & There is someone at work who encourages my development \\
\hline & My supervisor or someone at work cares about me as a person \\
\hline \multirow[t]{2}{*}{ Service Capability } & $\begin{array}{l}\text { My (Restaurant/Lodging??) offers excellent level of service to } \\
\text { its customers }\end{array}$ \\
\hline & $\begin{array}{l}\text { My company provides the information systems to enable me to } \\
\text { do my job properly }\end{array}$ \\
\hline Employee Satisfaction & How satisfied are you with your (??) as a place to work? \\
\hline \multirow[t]{4}{*}{ Employee Loyalty } & I intend to be working for this company three years from now \\
\hline & Labor turnover \\
\hline & Labor stability \\
\hline & Absenteeism \\
\hline Customer Satisfaction (Phase 1) & Overall customer satisfaction \\
\hline \multirow[t]{2}{*}{ Customer Loyalty (Phase 1) } & Likelihood to recommend \\
\hline & Likelihood to revisit \\
\hline
\end{tabular}

To assess agreement on organizational policy, behavioral expectation scaling procedures provide an analysis of the clarity of organizational policy within the level on which the scales are developed. For scale development, items with large variances are often discarded, but those may be the most important items for organizational development, because items with large variances pinpoint areas where organizational policy is unclear or in conflict.

Table 3. Sample Incident Questionnaire

Think back over the last year, or since you started working as a (depends on service provider). Focus your attention on any
specific thing that you saw a (could be co-worker, manager, etc.) do that make you think of him/her as a highly effective worker,
an average worker, a very ineffective worker, or any shade of effectiveness in between. Think of examples of what you saw or
heard a person do on the job that gave you some feeling for how well the individual was doing his/her job.
Write down what the person did; not what you conclude from his/her actions.
For example, a waiter changed the guest's order without comment although he/she knew what was brought was what the guest
originally ordered. Performance situations are those "things or activities" a (depends on service provider) encounters as part of
the job. Remember all situations are important - no situation is to trivial to report. Below list ten situations that come to mind


The fourth phase (Objectives 5 and 6) is to assess the Service Quality Information System following the work by Berry and Parasuraman (1997). According to their study, a service-quality information system can be beneficial only if used by decision makers (e.g. employees during service encounters). For that reason, it must be a communications system not just for data collection. A service-quality information system uses multiple research approaches to systematically capture, organize, and disseminate service-quality information to support organizational policy (service standards) and decision making. Determining who receives what information in what form and when is a principal design challenge. As part of the employee satisfaction assessment (phase 2), predesign questions would be asked, such as "What type of information would help you improve service in our company?" followed by post-implementation feedback questions, such as "What information on customer service would you like to receive that you currently do not receive? How would this additional information help you?" This assessment/feedback should revolve around what information different kinds of employees need to help them make good decisions and how and when to communicate the information.

This proposed methodology should determine the needs of the organization and its policies, and how the policies are communicated. Following the work of Blood (1974), Berry and Parasuraman (1997), and Jacobs et al. (1980) questions should be asked of employees to assess the accuracy of communication of organizational policy using behavioral expectation scaling procedures where members of the organization rate the job behavior items according to whether the behavior represents effective or ineffective job performance. The scale value for an item is then established as the mean rating. Item means can be collected for the same items from members at two different organization levels to indicate how well policy has been communicated between levels.

To assess agreement on organizational policy, behavioral expectation scaling procedures provide an analysis of the clarity of organizational policy within the level on which the scales are developed. For scale development, items with large variances are often discarded, but those may be the most important items for organizational development, because items with large variances pinpoint areas where organizational policy is unclear or in conflict.

The fifth phase of the study establishes a training approach that supplements and complements the knowledge (cognitive domain), the task-analysis (psychomotor domain), and skill training methods (psychomotor domain), by focusing on behaviors directly associated with job performance (affective domain) following the work of Goodman (1979) and Nadler (1971) and based upon the work above. Cross-departmental teams would be created where individuals within the organization are trained to lead the behavioral training. Once the assessment is completed, an assessment of the organizations approach to training to the task- and skill-training methods, by focusing on behaviors directly associated with job performance. In designing the training programs, the goal is to teach employees the things most critical to effective performance. A detailed analysis would be undertaken to determine precisely what employees need to know. This assessment would consider whether task (psychomotor) skills and learned outcomes (cognitive) are appropriately delivered. While it is nearly impossible to control employees' behavior in a given service encounter (point of consumption), the purpose of training is two-fold. First to increase the frequency of those important behaviors that are considered effective and second to extinguish the important behaviors considered ineffective.

The final phase is to re-assess, by following the procedures in phases 1 and 2, customer and employee service quality expectations and organizational performance, with the goal of enhancing employees' service delivery, and ultimately improve organizational performance. This should be accomplished at a point after phases 3 - 5; have been completed. During this final phase, the index calculated at the end of phase 2, should be recalculated and compared to the earlier index to determine if there has been any improvement. Management's goal is to reduce the indexed gap. As part of the strategic plan, continued monitoring of the index through the use of the proposed methodology should be set according to appropriate intervals and on the extent of the indexed gap.

\section{POTENTIAL IMPLICATIONS OF THE PROPOSED METHODOLOGY}

Quality is an elusive and indistinct characteristic, often mistaken for vague adjectives like exceptional or magnificent. Quality and its requirements are not easily expressed by consumers, and thus explanation and measurement of quality can present problems. As previous studies have demonstrated quality has often bypassed 
definitions and used uni-dimensional self-reporting measures to capture the explanation and measurement of quality (e.g. SERVQUAL, SERVPREF). At the same time, other quality studies have attempted to study employees using uni-dimensional reporting measures of organizational citizenship behavior (Bienstock et al., 2003) or through understanding service qualities and behaviors with service-quality information systems. Finally, studies have attempted to measure quality through behavioral assessments (e.g. Bitner et al., 1980; Goodman, 1979). Yet, none of these models looked at the entire picture as one continuous assessment and feedback process.

The proposed methodology in this study considers behavioral expectation assessment strategies, as the focal point, to understanding and improving service quality. These behavioral strategies link customer expectation and performance assessments used in previous studies as a means to develop employee selection and placement criteria, training programs, performance evaluation, assessment of the agreement on organizational policy, the communication of the organizational policy to employees and managers, and finally meaningful feedback through routine assessment of consumers and employees.

In summary, the benefit that the proposed LEGO model offers, by combining previous research in customer expectations and performance with the applications of CIT in the workplace, is $360^{\circ}$ feedback (Garavan et al., 1997) that can help service companies link the critical competency factors that connect job requirements with business objectives. Using the methods in this proposed model of assessment and feedback enables the confidential and anonymous collection of feedback from any number of people about the performance of an individual, a team, or an entire organization. This improved organizational performance can be evaluated against the expectationsperformance instrument both as a pre-test and post-test using the Lego model as presented in this paper.

\section{AUTHOR INFORMATION}

Nelson Barber, Ph.D., Associate Professor, The Whittemore School of Business and Economics, Department of Hospitality Management, University of New Hampshire, Durham, New Hampshire, 03824, 603-862-3303, e-mail: Nelsonbarber@msn.com. Dr. Barber has taught courses in advanced wine/beverage management, international food and culture, food and beverage operations, and graduate level marketing and finance. His research has been published in Managing Service Quality, Journal of Travel and Tourism Marketing, Journal of Hospitality Marketing and Management, Journal of Consumer Marketing, and many others. His MS is from Purdue University and PhD from Texas Tech University. His research focuses on various dimensions wine tourism, wine marketing, and decision behavior. E-mail: Nelsonbarber@msn.com.

Raymond Goodman, Jr., PhD, Professor, The Whittemore School of Business and Economics, Department of Hospitality Management, University of New Hampshire, Durham, New Hampshire, 03824, 603-862-3304, e-mail: Raygoodman@aol.com, Dr. Goodman has taught courses in introduction to the hospitality industry, human resource management, strategic management, and lodging and restaurant industry operations. He has written three books, and his research has been published in the Cornell Quarterly among others, and has published a monthly column, the Lodging Executives Sentiment Index, in Lodging Hospitality Magazine. His Masters and $\mathrm{PhD}$ in Hotel Administration are from Cornell University. His outreach focuses on retirement facilities planning, design, marketing, management and operations. E-mail: Raygoodman@aol.com

\section{REFERENCES}

1. Adams, J. S. (1965). Inequity in social exchange. In L. Berkowitz (Ed.), Advances in experimental psychology (Vol. 2, pp. 267-299). New York: Academic Press.

2. Arnold, E.J. and Price, L.L. (1993). River Magic: extraordinary experience and the extended service encounter. Journal of Consumer Research, 20, 24-45.

3. Berry, L. and Parasuraman, A. (1997). Listening to the Customer - The Concept of a Service-Quality Information System. Sloan Management Review/Spring, 65-76.

4. Bienstock, C., Demoranville, C. and Smith, R. (2003). Organizational citizenship behavior and service quality. Journal of Services Marketing, 17(4), $357-378$.

5. Bitner, M. (1990). Evaluating Service Encounters: The Effects of Physical Surroundings and Employee Responses. Journal of Marketing. 
6. Bitner, M., Booms, B. and Mohr, L. (1994). Critical Service Encounters: The Employee's View. Journal of Marketing, 58 (October), 95-106.

7. Bitner, M., Booms, B. and Tetreault, M. (1989). Critical Incidents in Service Encounters, in Designing a Winning Strategy, Mary Jo Bitner and Lawrence A. Crosby, eds. Chicago: American Marketing Association, 98-99.

8. Bitner, M., Booms, B. and Tetreault, M. (1990). The Service Encounter: Diagnosing Favorable and Unfavorable Incidents, The Journal of Marketing, 54(1), 71-84.

9. Blau, P. M. (1964). Exchange and power in social life. New York: John Wiley.

10. Blood, M. (1974). Spin-offs from behavioral expectation scale procedures. Journal of Applied Psychology, 59(4), $513-515$.

11. Bolton, R. and Drew, J.H. (1991). A multistage model of customers' assessments of service quality and value. Journal of Consumer Research, 17(4), 375-84.

12. Bolton, R. and Drew, J. (1994). Linking customer satisfaction to service operations and outcomes. Roland T. Rust, Richard L. Oliver eds., Service Quality: New Directions in Theory and Practice. Sage Publications, Thousand Oaks, CA, 173-200.

13. Brady, M. and Cronin, J. (2001). Some New Thoughts on Conceptualizing Perceived Service Quality: A Hierarchical Approach. Journal of Marketing, 65(3), 34-50.

14. Brady, M., Cronin, J. and Brand, R. (2002). Performance-only measurement of service quality: a replication and extension. Journal of Business Research, 55, 17- 31.

15. Brown, S. and Swartz, T. (1989). A Gap Analysis of Professional Service Quality. The Journal of Marketing, 53( 2), 92-98

16. Carlzon, J. (1987). Moments of Truth. Ballinger Publishing Company: New York

17. Cronin, J. and Taylor, S. (1992). Measuring Service Quality: A reexamination and Extension. The Journal of Marketing, 56(3), 55-68.

18. Eichengreen, B. and Gupta, P. (2009). The two waves of service sector growth: A Working Paper, No. 14968. National Bureau of Economic Research, 1050 Massachusetts Avenue Cambridge, MA 02138, Retrieved from http://www.nber.org/papers/w14968 .

19. Fishbein, M., \& Ajzen, I. (1975). Belief, attitude, intention, and behavior: An introduction to theory and research. Reading, MA: Addison-Wesley

20. Goodman, R. (1979). The Use of Critical Incident Methodology Applied to the Development of Waiter/Waitress Training Programs. Dissertation Abstracts.

21. Grapentine, T. (1998). The history and future of service quality assessment, Marketing Research: A Magazine of Management \& Applications 10 (4), 5-20.

22. Gremler, D. (2004). The Critical Incident Technique in Service Research. Journal of Service Research, $7(1), 65$.

23. Gronroos, C. (1982) Strategic Management and Marketing in the Service Sector (London, Chartwell Bratt).

24. Heskett, J., Jones, T., Loveman, G., Sasser, E. and Schlesinger, L. (1994). Putting the service-profit chain to work. Harvard Business Review, 72(2), 164-174.

25. Heskett, J. L., Jones, T. O., Loveman, G. W., Sasser Jr., W. E., \& Schlesinger, L. A. (2000). Putting the service-profit chain to work. (Product No. 4460, HBR On Point). Cambridge, MA: Harvard Business School Publishing Corporation.

26. Kelley, SW., Hoffman, KD. and Davis, MA. (1993). A Typology of Retail Failures and Recoveries. Journal of Retailing, 69 (Winter), 429-54.

27. Jacobs, R., Kafry, D. and Zedeck, S. (1980). Expectations of Behaviorally Anchored Rating Scales. Personnel Psychology, 33(3), 595-640.

28. Jain, S. and Gupta, G. (2004). Measuring Service Quality: SERVQUAL vs. SERVPERF Scales. VIKALPA, 29(2), 25 - 37.

29. Johnston, R. (1995), "The determinants of service quality: satisfiers and dissatisfiers", International Journal of Service Industry Management, 6(5), 53-71.

30. Lui, C. M. (2005). The Multidimensional and Hierarchical Structure of Perceived Quality and Customer Satisfaction. International Journal of Management, 22 (3), 426-435.

31. Nadler, L. 91971). Using critical events to develop training programs, Part I - assessment of needs and Part II - Building the training programs. Industrial Training International, 53-60. 
32. Oh, H. (1999). Service quality, customer satisfaction, and customer value: a holistic perspective. International Journal of Hospitality Management, 18(1), 67-82.

33. Oh, H. and Jeong, M. (1996). Improving marketers' predictive power of customer satisfaction on expectation-based target market levels. Hospitality Research Journal, 19(4), 65-86.

34. Ostroff, C., \& Bowen, D. E. (2000). Moving HR to a higher level. HR practices and organizational effectiveness. In K. J. Klein \& S. W. J. Kozlowski (Eds.), Multilevel theory, research, and methods in organizational psychology (pp. 211-266). San Francisco, CA: Jossey-Bass.

35. Parasuraman, A., Zeithaml, V.A. and Berry, L.L. (1985) A conceptual model of service quality and its implications for future research. Journal of Marketing, 49, pp. $41 \pm 50$.

36. Parasuraman, A., Zeithaml, V.A. and Berry, L.L. (1988). SERVQUAL: a multiple-item scale for measuring customer perceptions of service quality. Journal of Retailing, 64(1), 12-40.

37. Pritchard, M. and Silvestro, R. (2005). Applying the service profit chain to analyse retail performance: The case of the managerial strait-jacket? International Journal of Service Industry Management, 16(4), 337356.

38. Schlesinger, L.A., Heskett, J.L. (1991). Breaking the cycle of failure in services. Sloan Management Review, 32 (3), 17-28.

39. Simons, T., \& Roberson, Q. (2003). Why managers should care about fairness: The effects of aggregate justice perceptions on organizational outcomes. Journal of Applied Psychology, 88,432-443.

40. Smith, R.A. and Houston, M.J. (1982). Script-based evaluations of satisfaction with services, in Berry, L., Shostack, G. and Upah, G. (Eds), Emerging Perspective on Services Marketing, AMA, Chicago, IL, pp. 5962 .

41. Solomon, M., Surprenant, C., Czepiel, J. and Gutman, E. (1985). A role theory perspective on dyadic interactions: the service encounter. Journal of Marketing, 49, pp. $99 \pm 111$.

42. Stauss, B. and Mang, P. (1999). Culture Shocks' in Inter-Cultural Service Encounters? Journal of Services Marketing, 13 (4/5), 329-46.

43. Teas, R. and Palan, M. (1997). The Realms of Scientific Meaning Framework for Constructing Theoretically Meaningful Nominal Definitions of Marketing Concepts. Journal of Marketing, 61 (April), 52-67.

44. Wilson, A., \& Frimpong, J. (2004). A reconceptualisation of the satisfaction-service performance thesis. Journal of Services Marketing, 18, 471-481.

45. Zeithaml, A.V., Parasuraman, A. and Berry, L. (1990). Delivering Quality Service: Balancing Customer Perceptions, Vol. 5, The Free Press, New York, NY, pp. 71-79.

46. Zeithaml, A.V., Berry, L and Parasuraman, A. (1996). The Behavioral Consequences of Service Quality. The Journal of Marketing, 60( 2), 31-46. 


\section{NOTES}

